\title{
Die Zukunft selber gestalten!
}

\section{Jürg Schlup}

Dr. med., Präsident der FMH

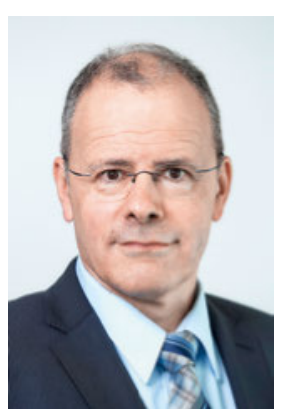

Zum neuen Jahr fragen wir uns häufig, was die Zukunft wohl bringen wird. Wir reflektieren, was gut lief und was wir verbessern könnten - weil wir intuitiv wissen, dass die Zukunft immer ein Kind der Gegenwart [1] ist: Wir können sie also selten voraussehen, aber häufig beeinflussen.

Was für unsere persönliche Zukunft gilt, trifft auch auf die Zukunft des Arztberufs zu. Bereits heute sind viele gesundheitspolitische Vorstösse aufgegleist, die das Jahr 2018 - und möglicherweise auch langfristig unsere berufliche Zukunft sowie die Zukunft unseres Berufs - prägen werden. Während die Aufmerksamkeit vieler Ärzte den Einbussen durch den zweiten bundesrätlichen Tarifeingriff gilt und die Frustration nachvollziehbar hohe Wellen schlägt, diskutiert das Parlament bereits die endgültige Abschaffung der Tarifautonomie zugunsten eines dauerhaften Staatstarifs. Darüber

\section{Die Ärzteschaft ist dann erfolgreich, wenn sie geeint und lösungsorientiert auftritt.}

hinaus sind - getrieben von der KostendämpfungsDiskussion - noch mehrere deutlich weitreichendere Regulierungsvorschläge auf dem Weg. Die Einführung ambulanter Operationslisten ohne gleichzeitige Einführung einer einheitlichen Finanzierung stationärambulant wird die Prämien erhöhen. Dies wird die Befürworter eines Globalbudgets für die OKP-finanzierte Gesundheitsversorgung stärken und somit der Rationierung den Weg ebnen. Auch die Pläne zur Zulassungssteuerung, die Vorstösse zur Abschaffung der freien Arztwahl und die Qualitätseinforderung über Sanktionen haben das Potential die gesamte Gesundheitsversorgung tiefgreifend und nachteilig zu verändern.

Wir sind 2018 also mit einigen Vorhaben konfrontiert, bei deren Umsetzung nicht nur der Patient auf der Strecke zu bleiben droht - auch der freie Arztberuf, wie wir ihn heute kennen, könnte bald der Vergangenheit angehören. Wenn ökonomische Ziele - seien es die der Politik, die der Krankenkassen oder die des Arbeitgebers - zwischen uns und dem Patienten stehen und unsere ärztliche Berufsausübung bestimmen, werden sich unsere Patienten fragen, was für uns handlungsleitend ist: ihr Gesundheitszustand oder die Budget- vorgaben? Ohne Unabhängigkeit ist unsere Glaubwürdigkeit und damit die unverzichtbare Vertrauensbeziehung zu unseren Patienten in Frage gestellt: Wir würden zu Administratoren von Patienten in einer kommerzialisierten Medizin.

Mark Twain sagte einst angeblich «Natürlich kümmere ich mich um die Zukunft. Ich habe vor, den Rest meines Lebens darin zu verbringen [2].» Ich hoffe, Sie halten es genauso. Nur erweisen sich manche Zukunftsentscheide leider später als kontraproduktiv: Es war die Ablehnung unseres eigenen Tarif-Revisions-Vorschlags in der Urabstimmung im Juni 2016, die der Politik die Vorlage für den zweiten Tarifeingriff lieferte und heute der Weichenstellung in Richtung Staatstarif als Legitimation dient. Gleichzeitig haben wir damit unsere Handlungsfähigkeit in einer entscheidenden politischen Phase beeinträchtigt.

Was können wir verbessern, damit aus dieser Gegenwart die bestmögliche Zukunft hervorgeht? Wir müssen als Teil der Lösung zusammenfinden! Die Ärzteschaft ist in der Regel dann erfolgreich, wenn sie geeint auftritt und lösungsorientiert Hand bietet. Dies heisst nicht nur, dass wir angesichts der anstehenden Herausforderungen konstruktiv argumentieren und Lösungen anbieten. Es heisst auch, dass wir einen gemeinsamen Tarif vorlegen müssen, auch wenn dieser mit Abstrichen verbunden sein wird. Denn der zweite Tarifeingriff muss schmerzhafter Höhepunkt einer schwie-

\section{Unsere Freiheit hat eine Zukunft, wenn wir} unserer Verantwortung gerecht werden.

rigen Tarifrevision bleiben und darf nicht zur Vorstufe eines noch schlimmeren Staatstarifs werden. Als Angehörige eines freien Berufs stehen wir in der Verantwortung, mit Blick auf die politischen Realitäten konstruktiv an Lösungen zu arbeiten. Ob unsere Freiheit eine Zukunft hat, ist auch abhängig davon, ob wir unserer Verantwortung gerecht werden.

\section{Literatur}

1 «Zukunft ist ein Kind der Gegenwart.» Christoph August Tiedge

2 Mark Twain (1835-1910), eigentlich Samuel Langhorne Clemens, US-amerikanischer Schriftsteller 